\title{
Screening for Retinopathy of Prematurity
}

\author{
Dr. Sonu Akhani ${ }^{1}$, Dr. Sucheta Munshi ${ }^{2}$, Dr. K. M. Mehariya ${ }^{3}$ \\ ${ }^{1}$ Third Year Resident, Civil Hospital, Ahmedabad, Gujarat, India \\ ${ }^{2}$ Associate Professor, Civil Hospital, Ahmedabad, Gujarat, India \\ ${ }^{3}$ Professor, Civil Hospital, Ahmedabad, Gujarat, India
}

\begin{abstract}
This study was carried out in 530 neonates to decide incidence of ROP and to determine association of weight and gestational age and incidence of ROP and to find out risk factors for ROP.
\end{abstract}

Keywords: ROP, Gestational age, $\mathrm{O}_{2}$ supplementation, sepsis, VLBW

\section{Introduction}

Retinopathy of prematurity (ROP) (Terry syndrome ) is a vasoproliferative retinopathy which affects developing retinal vasculature of premature babies. ${ }^{(1)}$ Retinopathy of prematurity (ROP) is a retinal disorder peculiar to premature infants potentially leading to blindness and severe visual impairment. $^{(2)}$ It is an important cause of childhood blindness all over the world. In India, with improved survival of very low birth weight (VLBW) infants, ROP is emerging as a significant problem even in developing countries like India. The development of neonatal intensive care units, preterm neonates with extremely low birth weights are surviving and are at an increased risk of developing $\mathrm{ROP}^{(3)}$. Providing these neonates with an intact survival is more important than merely reducing the mortality. The overall incidence of ROP in India is 0.1 per 1000 live birth. In developed countries the incidence of ROP is $90 \%$ among $<750 \mathrm{gm}, 78.2 \%$ among $750-999 \mathrm{gm}$ and $46.9 \%$ among $1000-1250$ gm babies.

\section{Materials and Methods}

To make this prospective observational study, 530 newborns (intramural+ extramural) are screened for ROP who were admitted in NICU of civil hospital, Ahmedabad, Gujarat during the period of September 2014 to March 2015.

\section{Inclusion Criteria}

a) Birth weight $<1.5 \mathrm{kgs}$.

b) Gestational age at birth $</=32$ weeks.

c) Birth weight $1.5-2 \mathrm{~kg}$ or age $>32$ wks of gestational age ; if risk factors are present.

- Respiratory distress syndrome.

- Sepsis.

- Multiple blood transfusions.

- Apneic episodes.

- Intra ventricular hemorrhage.

- Prolonged oxygen therapy.

Those whose gestational age is beyond 28 weeks first screening was done at 3-4 weeks of postnatal age and those whose gestational age is less than 28 weeks or weighing less than 1200 grams are screened fist at $31^{\text {st }}$ week of gestational age.

\section{Observation and Results}

Table 1: Overall Incidence

\begin{tabular}{|c|c|c|}
\hline Total Neonates & Neonates With ROP & Incidence \\
\hline 530 & 87 & $16.4 \%$ \\
\hline
\end{tabular}

Table 2: Gestational age and ROP staging

\begin{tabular}{|c|c|c|c|c|}
\hline \multirow{2}{*}{ ROP } & \multicolumn{3}{|c|}{ No. of Patients Positive For ROP } & Total no of \\
\cline { 2 - 4 } & $\begin{array}{c}<28 \text { WKS } \\
(n=28)\end{array}$ & $\begin{array}{c}28-32 \text { WKS } \\
(n=51)\end{array}$ & $\begin{array}{c}>32 \text { WKS } \\
(n=8)\end{array}$ & $(n=87)$ \\
\hline Stage 1 & 18 & 46 & 7 & 71 \\
\hline Stage 2 & 7 & 4 & 1 & 12 \\
\hline Stage 3 & 3 & 1 & 0 & 4 \\
\hline Stage 4 & 0 & 0 & 0 & 0 \\
\hline Stage 5 & 0 & 0 & 0 & 0 \\
\hline
\end{tabular}

Table 3: Birth Weight and ROP

\begin{tabular}{|c|c|c|c|}
\hline Weight & Total Patients & ROP Positive & Percentage \\
\hline$<1.5 \mathrm{KG}$ & 280 & 77 & $27 \%$ \\
\hline $1.5-2 \mathrm{KG}$ & 150 & 10 & $6.60 \%$ \\
\hline
\end{tabular}

Table 4: Neonatal Risk Factors and ROP

\begin{tabular}{|c|c|c|}
\hline Neonatal Risk Factors & $\begin{array}{c}\text { Frequency } \\
(n=530)\end{array}$ & $\begin{array}{c}\text { ROP Positive } \\
\text { Neonates }\end{array}$ \\
\hline Prematurity & $466(88 \%)$ & $77(16.5 \%)$ \\
\hline Oxygen Supplementation & $344(65 \%)$ & $79(22.9 \%)$ \\
\hline RDS & $180(34 \%)$ & $40(22 \%)$ \\
\hline Intraventricular Hemorrhage & $37(7 \%)$ & $4(11.6 \%)$ \\
\hline Apneic Spells & $22(42 \%)$ & $16(7.2 \%)$ \\
\hline Sepsis & $84(16 \%)$ & $13(15.4 \%)$ \\
\hline
\end{tabular}

Table 5: $\mathrm{O}_{2}$ supplementation and ROP

\begin{tabular}{|c|c|c|c|}
\hline & $\begin{array}{c}\text { Patients developed } \\
\text { ROP }\end{array}$ & $\begin{array}{c}\text { Patients not } \\
\text { developed ROP }\end{array}$ & Total \\
\hline $\mathrm{O}_{2}$ given & 79 & 288 & 367 \\
\hline $\mathrm{O}_{2}$ not given & 8 & 155 & 163 \\
\hline Total & 87 & 443 & 530 \\
\hline
\end{tabular}

\section{Discussion}

My study includes 530 neonates with incidence of $16.4 \%$ of ROP. Incidence among male is $13.5 \%$ which lower as compared to incidence among female babies which is $26.5 \%$ with sex ratio of 0.57 . Incidence of ROP is higher in babies

\section{Volume 4 Issue 12, December 2015}


with less than 28 weeks (37\%) and between 28 to 32 weeks (29\%) of gestational age as compared to incidence among babies with more than 32 weeks of gestational age. Maximum patients were diagnosed in stage 1(71) while none of them were diagnosed as having stage 5 ROP. Apart from gestational age, birth weight less than 1500 grams is one of the main risk factor as having high incidence of $27 \%$. Oxygen supplementation stands first as a major risk factor with incidence of $22.9 \%$ followed by RDS (22\%) and prematurity (16.5\%). Relative risk of oxygen supplementation is 4.38 .

\section{Conclusion}

Incidence increases with decreasing gestational age. Incidence is more common in neonates $<1.5 \mathrm{~kg}$. Oxygen administration was found to have positive correlation. Other risk factors that should be considered are RDS, apneic spells, sepsis, intraventricular hemorrhage.

\section{References}

[1] mechanisms and management of retinopathy of prematurity www.ncbi.nlm.nih.gov > ncbi > literature > pubmed central (pmc)

[2] facts about retinopathy of prematurity (rop) | national eye ...https://nei.nih.gov/health/rop/rop

[3] [pdf]aiims- nicu protocols 2010 retinopathy of prematurity

...www.newbornwhocc.org/pdf/rop_140810_300810.pd $\mathrm{f}$

[4] [pdf]retinopathy of prematurity in a tertiary care center medind medind.nic.in/ibv/t09/i3/ibvt09i3p219.pdf

[5] pdf]retinopathy of prematurity (rop) - ontop www.ontop-in.org/ontop-pen/week-1213/rop_final_final.pd

[6] pdf]retinopathy of prematurity - vision 2020 e-resource v2020eresource.org/content/files/nnf.html

[7] pdf]full text pdf www.jcbsonline.ac.in/articles/jcbs\%20$\% 203 \% 20(2) \_32-36 . p d f$

[8] retinopathy of prematurity in babies weighing $<1800 \mathrm{~g}$; with $\quad \ldots \quad$ www.ijmedph.org/article. asp?issn=22308598; year2014;..

[9] mobile screening for retinopathy of prematurity: the ...retinatoday.com/.../mobile-screening-for-retinopathyof-prematurity-the-..

[10]dr azad on rop: need for training and screening slideshare www.slideshare.net/retinaindia/3-rop-needfor-training-and-screeningdr-..

[11]pdf]april to june $2013 \quad-\quad n p c b$ npcb.nic.in/writereaddata/mainlinkfile/file312.pdf

[12]pdf]retinopathy of prematurity: an update - sankara nethralaya www.sankaranethralaya.org/insight/pdf\%20files/.../11_r etinopa.pd

[13] karnataka internet assisted diagnosis of retinopathy of ... www.narayananethralaya.org/karnataka-internetassisted-diagnosis-of-ret..

[14] rop affects about $30-50$ per cent of premature babies in India

www.financialexpress.com/article/healthcare/.../rop...in $\mathrm{dia} / 17289 /$ 